\title{
Apoio de Terapia Ocupacional para a participação escolar de criança com artrogripose múltipla congênita: um estudo de caso
}

\author{
Bianca Sampaio Fiorini* \\ Rita de Cássia Tibério Araújo**
}

\section{Resumo}

A artrogripose múltipla congênita (AMC) é uma doença rara e tem como característica o comprometimento em múltiplas articulaçóes, que interfere no desempenho de atividades de vida diária (AVDs) e escolares. A tecnologia assistiva é uma área do conhecimento que engloba recursos, adaptaçóes, metodologia, estratégias, serviços que visam promover maior independência e participação de pessoas com deficiência, incapacidade ou com mobilidade reduzida em diversos contextos. O terapeuta ocupacional é um profissional que utiliza a tecnologia assistiva a fim de auxiliar o indivíduo a desenvolver suas potencialidades e adquirir maior independência nas atividades cotidianas. O presente estudo teve por objetivo relatar a experiência de uma intervenção de terapia ocupacional direcionada às necessidades de uma criança com artrogripose múltipla congênita (AMC), no que tange às dificuldades para realização de tarefas gerais no contexto escolar. Trata-se de um estudo descritivo, do tipo estudo de caso. Realizou-se intervenção, durante um ano, com uma criança matriculada em sala regular de Ensino Fundamental. Realizaram-se visitas escolares para identificação de demandas, conjuntamente com a professora da participante, visando prescriçáo, confecção e aplicaçáo de recursos adaptados. Elaborou-se um roteiro de entrevista semiestruturado para verificar a percepçáo da professora a respeito do uso dos recursos confeccionados. As adaptaçóes auxiliaram e facilitaram o desempenho nas atividades de autocuidado, como também em tarefas que envolviam a utilização de materiais escolares. O trabalho conjunto do profissional da saúde com o profissional da educação foi percebido pela professora da participante como algo que favorece condutas mais pontuais na resolução de problemas de participação escolar.

Palavras-chave: Terapia Ocupacional; Educação Especial; Tecnologia Assistiva.

\footnotetext{
* Terapeuta ocupacional graduada pela Universidade Estadual Paulista Júlio de Mesquita Filho. Marília, São Paulo, Brasil.

** Professora doutora da Universidade Estadual Paulista Júlio de Mesquita Filho. Marília, São Paulo, Brasil.
} 


\section{Occupational Therapy support for the school attendance of a child with arthrogryposis multiplex congenita: a case study}

\section{Abstract}

The arthrogryposis multiplex congenita (AMC) is a rare disease and is characterized by impairment in multiple joints, which affects the performance of Activities of Daily Living (ADL) and school activities. Assistive technology is an area of knowledge that encompasses resources, adaptations, methodology, strategies and services that aimsto promote greater independence and participation of people with disabilities, impairments or reduced mobility in different contexts. The occupational therapist is a professional who uses assistive technology in order to assist the individual to develop their potential and gain greater independence in their daily activities. This study aimed to report the experience of an occupational therapy intervention directed to the needs of a child with arthrogryposis multiplex congenita (AMC), in relation to the difficulties to perform general tasks in the school context. This is a descriptive study of a case study. The intervention was carried out over a year with a child enrolled in regular class elementary school. School visits for identifying demands were held jointly with the teacher participant seeking prescription, preparation and implementation of tailored resources. A semi-structured interview script was elaborated to verify the perception of the teacher regarding the resources' use. The adjustments helped and facilitated performance in self-care activities as well as in tasks involving the use of school supplies. The joint work of the health professional with the education professional was perceived by the teacher participant as something that favors more specific behaviors in solving problems of school participation.

Keywords: Occupational Therapy; Special Education; Assistive Technology.

\section{Introdução}

O termo artrogripose é utilizado para nomear um grupo de doenças que apresentam como característica comum múltiplas contraturas articulares, como também contratura articular rígida (FILHO; SANTOS, 2006).

De acordo com os autores supracitados, a artrogripose múltipla congênita (AMC) é uma doença rara e possui etiologia multifatorial; o diagnóstico se dá por exames clínicos ao nascimento, os quais são importantes para verificar se há limitações de movimento em pelo menos três articulaçôes.

Em relação aos aspectos clínicos, há variabilidade nos casos assim como na severidade, observando-se características predominantes nos pacientes, umas delas é a aparência dos membros que não possuem formato padrão, mas sim tubular. Em membros superiores, é comumente observado ombros em adução e rotação interna, cotovelos em extensão, podendo apresentar rigidez, pronação de antebraços, rigidez 
de punhos em flexão com desvio ulnar; nas mãos observam-se articulações metacarpofalangeanas fletidas, interfalangeanas em extensão e polegares aduzidos (CHICONELLI; MONTEIRO, 1994; ANDRADE, 2003).

Em virtude das características do diagnóstico, o indivíduo apresenta dificuldades em diversas atividades do cotidiano devido ao comprometimento motor que interfere na sua independência para realizá-las. $\mathrm{O}$ tratamento deve ser precoce e a participação de uma equipe multidisciplinar é imprescindível nesse contexto (ANDRADE, 2003).

As atividades do cotidiano englobam as atividades de vida diária (AVDs) que são desenvolvidas em diversos ambientes, como, por exemplo, em casa, na escola ou também em local de trabalho (MELLO; MANCINI, 2007).

O terapeuta ocupacional utiliza-se da tecnologia assistiva para estimular a função e contribuir na aquisição de maior independência nas atividades funcionais (BARTALOTTI; DE CARLO, 2001; PELOSI, 2007; TREVISAN; BARBA, 2012).

A tecnologia assistiva pode ser definida como uma área do conhecimento que compreende uma série de recursos, estratégias, metodologias, práticas e serviços, os quais têm como objetivos promover a funcionalidade, desenvolver a autonomia e participação de pessoas com deficiência em diversos contextos, buscar maior qualidade de vida e inclusão (CAT, 2007; BRASIL, 2007; PELOSI, 2010).

A partir desta perspectiva, ao se pensar na independência da pessoa com AMC e na participação em diversos contextos, o terapeuta ocupacional pode prescrever adaptaçôes ajustadas às especificidades do usuário como procedimento de tecnologia assistiva (ANDRADE, 2003). A adaptação contempla a modificação de uma tarefa, método ou ambiente com a finalidade de promover independência e ampliar a funcionalidade (TEIXEIRA; ARIGA; YASSUKO, 2003).

Ao se pensar na prescrição e confecção adequadas, é necessária a identificação de dificuldades observadas quando o cliente realiza suas atividades ou a partir de informaçôes dadas através da família sobre as reais necessidades e, para isto, é imprescindível a avaliação pelo terapeuta ocupacional (ALMEIDA; LIMA, 2011).

O trabalho do terapeuta ocupacional tem se revelado importante no âmbito escolar, como facilitador da relação escola-aluno-família, para apoiar a inclusão de todas as crianças (TREVISAN; BARBA, 2012) e, também, integrar a equipe escolar para desenvolvimento de açóes conjuntas ao professor com o objetivo de superar barreiras para a inclusáo efetiva (BARTALOTTI, 2007).

$\mathrm{O}$ uso de recursos de tecnologia assistiva, além de beneficiar o desempenho em diversas situaçóes, contribui na aquisição de maior autonomia no contexto escolar, propiciando condiçóes de permanência e bom desempenho na escola, em concordância com princípios de cidadania (MARINS; EMMEL, 2011).

A artrogripose, sendo uma afecção de origem congênita, caracteriza-se como deficiência física, conforme artigo $4^{\circ}$ do Decreto Lei n. 3.298, de 20 de dezembro de 1999 (BRASIL, 1999). 
Dentre as dificuldades que a pessoa com deficiência física pode apresentar em seu cotidiano, encontram-se: dificuldades no uso manual para manipular objetos ou utilizar utensílios de escrita; realizar atividades de vida diária, como, por exemplo, atividades de autocuidado (PELOSI, 2008). De acordo com Marins e Emmel (2011), ao fazer adaptaçóes para algum uso em específico, sejam de baixa, média ou alta tecnologia, o planejamento deve atender às necessidades do indivíduo e objetivar melhor funcionalidade.

Levando-se em consideração os aspectos supracitados, observa-se a importância em prescrever e confeccionar recursos de baixa tecnologia, sendo estes adaptaçóes, que favoreçam o desempenho em atividades do cotidiano à pessoa que necessita destes dispositivos. Com isto, o presente estudo teve por objetivo relatar a experiência de uma intervenção de terapia ocupacional direcionada às necessidades de uma criança com artrogripose múltipla congênita (AMC), no que tange às dificuldades para realização de tarefas gerais no contexto escolar.

\section{Método}

Trata-se de um estudo descritivo, do tipo estudo de caso. O trabalho realizouse a partir da intervençáo, ao longo de um ano, no programa de aprimoramento profissional de Terapia Ocupacional, sendo um atendimento a cada semana com duraçáo de uma hora. Também foram feitas visitas à escola para observação e identificaçáo de demandas necessárias, a fim de favorecer o desempenho nas atividades escolares. Para obtençáo de informaçóes sobre o cotidiano da aluna na escola, bem como de suas necessidades, utilizou-se um caderno para trocas comunicativas com o professor.

A partir desse levantamento, foram prescritos e confeccionados recursos adaptados para auxílio no desempenho das atividades. $\mathrm{O}$ uso desses recursos, no ambiente escolar, foi avaliado segundo a percepção do professor. Para isso, elaborou-se um roteiro de entrevista semiestruturado, que abordou três temas: a) recursos de tecnologia assistiva (contribuiçáo dos recursos confeccionados para a criança, se estes facilitaram o desempenho nas atividades, se houve alguma barreira em relação ao uso); b) parceria entre o professor e terapeuta ocupacional (o trabalho conjunto entre esses profissionais com o objetivo de favorecer a participação do aluno nas atividades escolares); c) orientação quanto à adequação do ambiente e à utilização de recurso de tecnologia assistiva (opiniáo do professor sobre a importância de maior contato com profissionais da saúde para apoio à experiência escolar do aluno com deficiência).

\section{Procedimentos éticos}

A presente pesquisa foi aprovada pelo Comitê de Ética em Pesquisa da Faculdade de Filosofia e Ciências da UNESP de Marília, sob o parecer n.1959/2009. Houve a concordância do participante/responsável, através do Termo de Consentimento Livre e Esclarecido, em participar de pesquisas pela instituição, a qual teve acompanhamento. 


\section{Participante}

A criança participante do trabalho, do sexo feminino, encontrava-se com sete anos de idade, na época do estudo, e frequentava sala regular de ensino fundamental. Em sala de aula, utilizava carteira adaptada para atender às medidas antropométricas em relação a melhor postura ao realizar as atividades, sendo, portanto, carteira mais baixa para possibilitar o manuseio dos materiais escolares, conforme prescriçóes do fisioterapeuta. A participante não possuía adaptaçôes de utensílios escolares e acompanhava as aulas sem dificuldades em relação aos conteúdos.

Em relação às características referentes ao diagnóstico de artrogripose múltipla congênita (AMC), realizada a avaliaçáo que contemplava aspectos psicomotores, aspectos percepto-cognitivos, comunicação, linguagem e atividades de vida diária (AVD), foi possível verificar, por meio de observação clínica, o quadro motor da participante, evidenciando-se: alteraçáo motora e fraqueza muscular em membros superiores e membros inferiores, além de contraturas em articulaçóes distais dos membros, causando limitação na mobilidade. No que se refere à funcionalidade, realizava atividades de escrita independentemente, com padrão de execução adaptado às suas condiçôes motoras, manuseava alguns utensílios escolares sem auxílio, porém, ainda apresentava dificuldades em atividades que exigiam preensão fina com demanda de força muscular para manutenção do objeto apreendido.

Além do acompanhamento por terapeuta ocupacional em um Centro de Atendimento especializado para crianças, jovens e adultos com deficiência, fazia, também, acompanhamento com fisioterapeuta de outra instituição.

A professora da participante graduou-se em Pedagogia por uma universidade pública, trabalhava na rede regular de ensino há sete anos, possuía habilitação em orientação educacional e em Educação Infantil, especialização em Atendimento Educacional Especializado (AEE) na área de deficiência intelectual.

\section{Local}

O presente estudo desenvolveu-se no Centro de Estudos da Educação e da Saúde (CEES) Faculdade de Filosofia e Ciências - Unesp - campus de Marília, onde é realizado o Programa de Aprimoramento Profissional de Terapia Ocupacional na interface entre a Ârea da Saúde e da Educação.

\section{Prescrição e confecção dos recursos adaptados}

A prescrição dos recursos ocorreu com base na observação da realização das atividades em sala de aula, como também a partir de dificuldades em algumas atividades de vida diária, evidenciadas pela própria criança durante as terapias ocupacionais.

Para a confecção dos recursos, foram considerados alguns aspectos importantes, tais como descritos por Trombly e Radomski (2005) que destacam sete itens a serem considerados quanto ao procedimento de adaptação: 
1. Analisar a tarefa, pois se torna necessário a identificação das habilidades do indivíduo juntamente ao ambiente ao qual está inserido;

2. Deteç̧ão do problema;

3. Reconhecer os princípios de compensação dos itens a serem adaptados;

4. Sugerir soluçóes: além de o terapeuta colocar em prática sua criatividade, é importante a colaboração neste aspecto tanto do cliente quanto da família;

5. Ter o conhecimento sobre as formas alternativas de recursos para resolução do problema;

6. Examinar o uso das adaptaçôes com regularidade em determinado tempo;

7. Treinar o uso da adaptaçáo objetivando a funcionalidade.

\section{Resultados}

A independência do indivíduo em determinada tarefa é um dos objetivos de intervençáo focalizados pelo terapeuta ocupacional, para esse fim, ele poderá utilizar meios alternativos, sendo um deles a prescrição de recursos ou adaptaçóes de tecnologia assistiva (HOLM; ROGERS; JAMES, 2002).

O recurso pode ser definido como um material concreto com características que podem ser modificadas ou adequadas de acordo com as especificidades e necessidades de uma pessoa (ARAÚJO; MANZINI, 2001; ROCHA, 2010).

A seguir, serão apresentados os recursos adaptados confeccionados, assim como suas características, materiais utilizados para confecção e objetivos.

\section{Recursos para atividades de autocuidado}

Conforme a American Occupational Therapy Association (2008), o maquiar-se e escovar o cabelo se incluem nas atividades de higiene pessoal e autocuidado dentre outros subitens que contemplam as atividades de vida diária (AVDs). As AVDs representam também, dentre outros aspectos, um papel importante na função social do indivíduo, além disso, configuram a identidade de cada sujeito, isto é, constitui sua forma de se expressar e em suas características pessoais, um exemplo disto são as atividades de barbear-se e maquiar-se (CAZEIRO et al., 2011). As atividades de autocuidado têm repercussão em diferentes ambientes de vida coletiva socialmente organizada, dentre os quais, o ambiente escolar.

\section{Recurso 1: adaptação de maquiagem}

A partir da análise em relação à utilização dos utensílios de maquiagem, considerando as características motoras e desempenho da criança nesta atividade, verificou-se a necessidade de alongar os pincéis de maquiagem, aumentar a base do estojo e acrescentar alça para abri-lo. Portanto, tiveram-se como objetivos: tornar o abrir e o fechar do estojo de maquiagem uma ação independente; contribuir no manuseio dos pincéis e alcance destes no rosto para facilitar a aplicação da maquiagem; melhorar a visualização no espelho ao realizar a atividade. 
A adaptação da maquiagem foi feita com a utilização dos seguintes materiais para sua confecção: E.V.A. colorido, cola quente, fita métrica e tesoura. As adaptaçôes foram testadas até que ficassem mais adequadas para o manuseio.

Como resultados, a adaptação facilitou o manuseio do estojo de maquiagem no sentido de fechá-lo e abri-lo, levando em consideração que, anteriormente, a criança não realizava estas açóes independentemente. $\mathrm{O}$ alongamento dos pincéis auxiliou a preensão e facilitou a visualizaçáo no espelho enquanto realizava a maquiagem, o que favoreceu o alinhamento postural na posiçáo sentada.

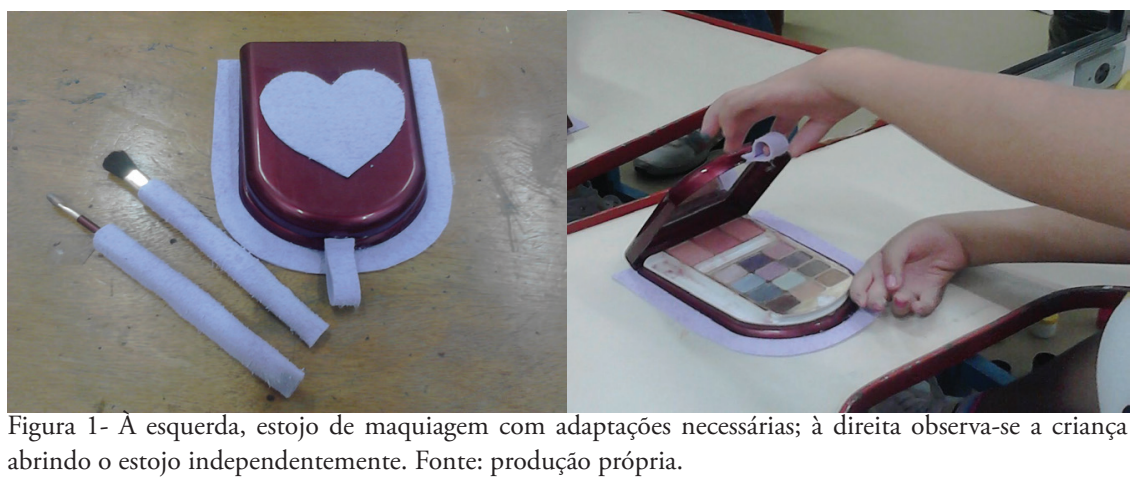

\section{Recurso 2: adaptação de escova de cabelo}

Foi realizada a análise da atividade utilizando escova sem adaptação, a fim de verificar as modificaçôes necessárias para que a criança executasse movimentos com maior independência. Observou-se a necessidade em adaptar o cabo da escova, alongando-o, devido às dificuldades na amplitude de movimento e na realização de movimentos de flexão de ombro e cotovelo, os quais são requeridos nesta atividade. Portanto, os objetivos da adaptação foram: facilitar o manuseio da escova com o cabo engrossado; melhorar o alcance posterior ao escovar os cabelos; tornar a realização da atividade de forma mais independente. Os materiais utilizados na confecção foram: cabo em plástico duro, E.V.A. colorido, cola quente, tesoura e ferramenta de corte para plásticos.

Referente aos resultados, pôde-se observar melhor desempenho ao realizar a atividade, sendo um fator relatado pela própria criança. O alongamento do cabo da escova facilitou o alcance em parte posterior dos cabelos, o que contribuiu na maior independência ao realizar a ação requerida. 


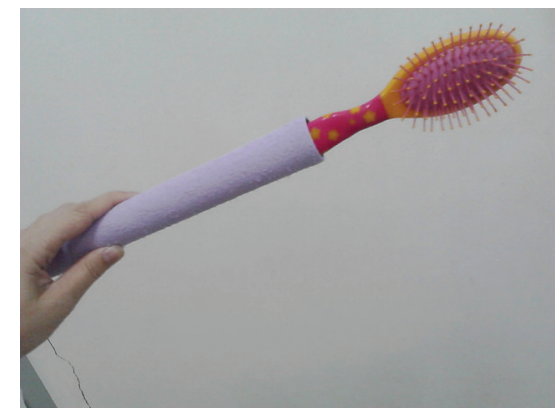

Figura 2 - Escova de cabelo com adaptaçáo do cabo, o qual foi alongado devido às necessidades da criança. Fonte: produção própria.

\section{Recursos para atividades em diferentes ambientes escolares}

O terapeuta ocupacional, além de estimular a independência nas AVDs, também atua na prescrição e aplicação de recursos para auxílio no desempenho das atividades escolares (ANDRADE, 2003). De acordo com o mesmo autor, há algumas adaptaçôes utilizadas com maior frequência pelas crianças com AMC, tais como adaptação de cabos e adequação na angulação de utensílios gráficos (lápis, canetas, giz de cera, entre outros objetos).

Ao se pensar na inclusão efetiva, é necessário identificar as barreiras que dificultam a participaçáo plena do aluno, deste modo, é importante pensar em estratégias e recursos que promovam acesso no contexto escolar. É nesse sentido que as adaptaçóes são essenciais para possibilitar a realização mais produtiva e independente das tarefas, sendo possível maximizar as capacidades das crianças com deficiência (TOYODA; CRUZ; LOURENÇO, 2009).

\section{Recurso 1: adaptação em alça para zíper de bolsas de uso escolar}

$\mathrm{O}$ uso de bolsa pela criança faz parte do cotidiano da vida escolar. A partir da observação da criança durante a utilizaçáo desse acessório, constatou-se dificuldade de desempenho para abrir e fechar a bolsa. Portanto, houve a necessidade de se confeccionar uma alça acoplada ao zíper para possibilitar e facilitar esta ação que exige preensão fina e força muscular. $\mathrm{O}$ objetivo da adaptação foi tornar a participante o mais independente possível para abrir e fechar bolsas. Para confecção da alça, utilizaram-se os seguintes materiais: E.V.A. colorido (escolha da cor de acordo com a preferência da participante), tesoura e cola quente. Diante disto, feita a adaptação nos zíperes, a criança executou a ação com maior facilidade e independência, demonstrando-se satisfeita com o resultado, pois a alça foi confeccionada de acordo com suas reais necessidades e contribuiu na realização da ação específica com maior independência. É válido ressaltar que se trata de uma adaptação simples, porém de grande valia quando se analisa as demandas para uso da bolsa. 

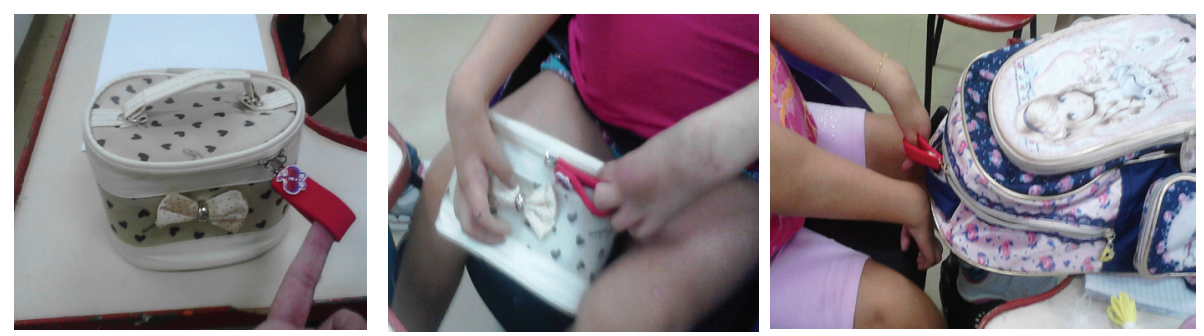

Figura 3 - Adaptação em zíper para facilitar preensão ao abrir e fechar. Observa-se ao centro e à direita a criança executando a ação independentemente. Fonte: produçáo própria.

\section{Recurso 2: adaptação em lápis e canetas hidrográficas}

Considerando-se as especificidades da criança participante do estudo, no que diz respeito às suas habilidades e características funcionais, verificou-se que ela se apropria de uma preensão em padrão considerado inadequado, porém funcional ao se pensar na realização efetiva das açôes que envolvem a escrita. Sua preensão ocorria com o apoio do lápis em antebraço e não fazia o uso tridigital, que é considerado adequado. O motivo de a criança realizar esta preensão decorre das contraturas em flexão nos punhos.

A partir da análise de atividades gráficas (escrita, pintura e desenho) que envolvem o uso de lápis, observou-se que, conforme estes eram utilizados, havia a necessidade de apontá-los, assim, ficavam menores e logo perdiam a utilidade, considerando as necessidades da criança. Também foi observado que as canetas hidrográficas dificultavam o uso por terem menor comprimento. Pensou-se em confeccionar duas adaptaçôes, uma que poderia ser encaixada em diversos lápis e outra para ser utilizada com as canetas hidrográficas. Essas adaptaçóes tiveram por objetivos: facilitar o uso das canetas hidrográficas e dos lápis; possibilitar melhor escrita e aumentar o tempo de uso tanto de lápis preto convencional quanto de lápis de cores.

Os materiais utilizados para a confecção foram: tubos em plástico de lapiseiras e canetas, que foram escolhidos de acordo com o diâmetro necessário para acoplarse adequadamente aos lápis e às canetas hidrográficas, E.V.A. colorido; cola quente; régua e tesoura. Foram feitos testes em relação à facilidade em colocar e retirar os adaptadores de modo que a criança o fizesse independentemente, assim ambos ficaram adequados.

Obtiveram-se como resultados das adaptaçóes confeccionadas: melhor desempenho na escrita, ampliando as habilidades funcionais da criança; o alongamento dos lápis e canetas hidrográficas facilitou a execuçáo das atividades com maior estabilidade preensão ao manusear os utensílios; houve a diminuição em relação à troca recorrente dos lápis quando estes ficavam um pouco menores, sendo um fator que contribuiu para o melhor aproveitamento dos objetos. 


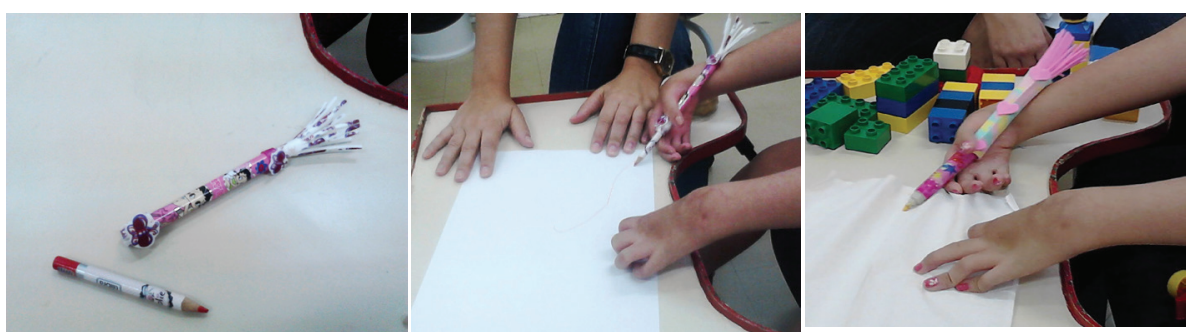

Figura 4 - Observa-se à esquerda a adaptação antes de ser acoplada ao lápis. Ao centro, a criança utiliza o lápis com adaptação. À direita, adaptação para caneta hidrográfica e a utilização desta pela criança. Fonte: produção própria.

\section{Recurso 3: virador de páginas}

As atividades escolares envolvendo leitura, utilização do caderno em casa ou na escola, ver uma revista ou gibi requerem várias açôes. O ato de virar a página, algo que pode parecer simples e automático, não era dominado pela criança, sendo esta dificuldade muito importante de ser observada quando se trata de favorecer a independência em tais situaçóes de manuseio. Deste modo, a confecção de um recurso para virar páginas, visando promover maior independência nas atividades de leitura ou quando se utiliza o caderno da escola, teve como requisito suprir a necessidade de preensão fina, de maneira que seu manuseio ocorresse com o uso de preensão grossa.

Os materiais utilizados na confecçáo foram: tubo de caneta comum do tipo esferográfica, cilindro de espuma em cor clara para engrossamento do virador de páginas e borracha do tipo ponteira. Para a confecção da boneca, pensando na atratividade do recurso utilizou-se: Isopor ${ }^{\oplus}$, E.V.A. colorido, material em pluma, canetas permanentes, cola quente e tesoura.

O acompanhamento do uso do recurso demonstrou que a adaptação atingiu os objetivos traçados, permitindo maior independência da criança tanto ao virar páginas de seu caderno de tarefas quanto ao ler ou utilizar os livros didáticos.
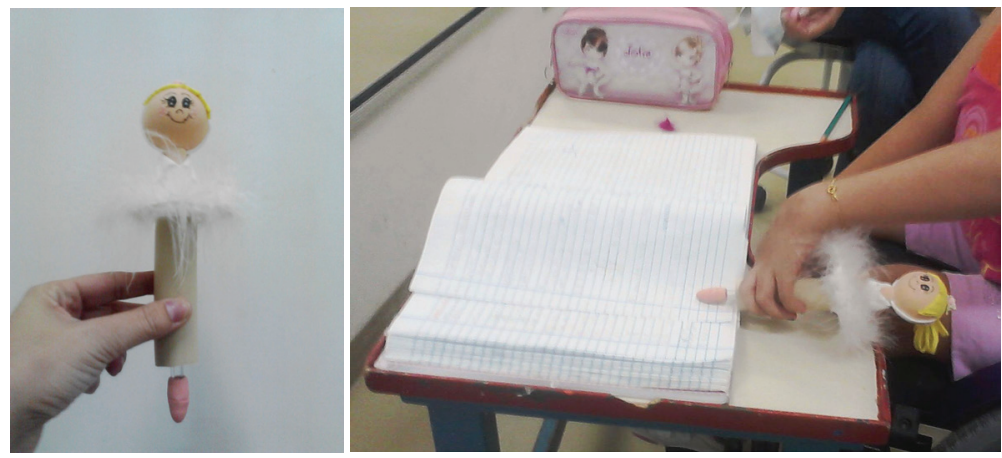

Figura 5 - À esquerda, virador de páginas confeccionado e à direita observa-se a criança utilizando-o ao virar as páginas de seu próprio caderno de tarefas. Fonte: produçâo própria. 


\section{Resultados da intervenção na percepção do professor}

Observa-se ser essencial o trabalho do terapeuta ocupacional ao se pensar no desempenho de atividades de vida diária, no sentido de promover maior independência, autonomia e, não menos importante, a autoestima do cliente. É também imprescindível o trabalho conjunto do terapeuta ocupacional e professor no processo de inclusão escolar. Em um estudo feito por Cardoso e Matsukura (2012), foi observada a relevância em se relacionar o cotidiano educacional de forma complementar à intervenção clínica, sobretudo na atuação do terapeuta ocupacional no contexto da escola regular. Os autores identificaram, através de questionário, que há uma forte prática deste profissional na orientação para o uso de tecnologia assistiva, bem como de adaptaçáo de recursos materiais e de espaços físicos em âmbito educacional.

Em relação à confecção dos recursos, a partir da entrevista realizada com a professora da participante, destaca-se o seguinte trecho, o qual permite notar a importância de sua percepção, visto que é ela quem acompanha a criança em seu cotidiano escolar:

"O alongador foi o que ela usou mais, tanto que ela não conseguia escrever mais se não fosse com o alongador, porque os lápis dela ficavam curtos e aí ela já tinha que inutilizá-los, e com o alongador isso não aconteceu, ela podia colocar qualquer lápis lá dentro que poderia usar até o finalzinho dele, foi um ganho pra ela. Com o virador de páginas foi bom, mas como era uma boneca enfeitada, as meninas começaram a ficar em cima para ela poder emprestar o virador para elas brincarem. Ela conseguiu virar as páginas, mas ainda percebi um pouco de dificuldade em relação a isso às vezes, por conta da força e precisão. Ela deu outra função ao recurso, apagava entáo com a ponteira de borracha, pois obteve ganhos e já conseguia sozinha virar as páginas, com a própria mão. As alças, a do estojo ela conseguia usar, porque o estojo ficava leve e estava em uma altura que ela poderia abrir o zíper dele, já a alça da bolsa, ficou difícil de usar por conta do peso da bolsa”.

É possível identificar que foram encontradas algumas variáveis em sala de aula quando a criança utilizou as adaptaçóes. Havendo, portanto, a necessidade de alternativas ou adequaçóes que facilitem o uso. Nesse sentido, nota-se a importância do contato constante entre os profissionais, a fim de verificar o uso dos recursos no dia a dia e sempre ajustados às demandas da atividade conforme as necessidades do aluno, considerando, também, o contexto em que ele se encontra.

A entrevista permitiu observar algumas questóes a respeito do trabalho conjunto entre professor e terapeuta ocupacional, bem como o papel deste profissional na escola e sua contribuição no atendimento de crianças com necessidades especiais. No estudo feito por Cardoso e Matsukura (2012), sobre a identificação das açóes desenvolvidas pela Terapia Ocupacional no processo de inclusão escolar de crianças com necessidades educacionais especiais, observou-se, dentre os resultados, pensando em políticas públicas, a necessidade em se obter maior investimento para a contratação 
do terapeuta ocupacional, a fim de contemplar a equipe de apoio. Deste modo, pode ser observado, na seguinte fala, o apontamento da professora da participante sobre a importância da contribuição do terapeuta ocupacional na escola.

\footnotetext{
"Para a escola, a função do terapeuta ocupacional é desconhecida, e seria interessante a participação do terapeuta em conjunto com a educação, no sentido de ajudar o professor e os alunos a melhorar questôes práticas do cotidiano que faz parte da escola, como por exemplo, desde como se deve segurar um lápis até questóes mais complicadas que envolvam alguma deficiência de um aluno. Não temos terapeuta no centro de atendimento multidisciplinar da prefeitura no caso, temos fisioterapeuta, fonoaudiólogo, mas ainda não temos a presença do terapeuta ocupacional. No caso da criança em questão, por exemplo, a diferença da participação do terapeuta foi enorme porque é importante ter a visão do dia a dia da criança e o que se deve fazer para melhorar a condiçáo da criança em suas atividades. E é um profissional que necessita observar, estar presente na sala para acompanhar o cotidiano da sala e elaborar uma intervençáo coerente, que a criança faça proveito disso. Seria o terapeuta ocupacional o profissional que vai observar quais são as dificuldades que ela enfrenta com sua condição, ele vai auxiliar nas suas atividades, de forma provisória, vendo os ganhos com o tempo, e depois perceber se há necessidade novamente de adaptaçôes e recursos para facilitar as atividades".
}

Por fim, observa-se, a seguir, a percepção da professora sobre orientação quanto à utilização de recursos de tecnologia assistiva e a necessidade de se adequar o ambiente a fim de auxiliar o aluno com deficiência e se estas açôes seriam facilitadas com a contribuição de outros profissionais, dentre eles o terapeuta ocupacional.

"Tem questôes que não fazem parte da formação do professor. Nada impede que uma profissão tome algum conhecimento que seja relativo à outra profissão, desde que seja no sentido de auxiliar a criança que tenha alguma dificuldade. Não sei sobre desenvolvimento motor, por exemplo, eu não sei sobre características a fundo sobre alguma deficiência. Quando meu aluno chega, me interessa saber quais a limitaçóes que ele tem e de que forma eu poso auxiliar. Se na sala náo consigo atender as necessidades do meu aluno, a superar suas dificuldades, porque não vou procurar um profissional que tenha outro olhar que vai além do pedagógico? Se a criança está dentro de um mundo, se é para haver a inclusão nada mais coerente uma equipe multidisciplinar envolvida. No caso da aluna em questáo, ela necessitou de algumas coisas, mas há coisas que não conseguimos fazer, porque não sabemos exatamente quais as condições físicas dela, para não prejudicar em nada em seu físico. Ela tem dificuldades em escrever, eu posso até tentar fazer algo que a auxilie, mas quem vai pensar efetivamente são esses profissionais como o terapeuta ocupacional, por exemplo, que vai atender. Eu náo teria tempo de fazer algumas adaptaçóes, com um pouco de 
pesquisa se consegue até se pensar algo para ela, mas a fica a dúvida: é o mais adequado? É o certo? Que são coisas que um profissional da área (saúde) faria melhor, que poderia avaliar se está adequado e se prejudica ou náo. É importante também o profissional ouvir o que professor tem a dizer, porque é ele quem vai dar dicas sobre as necessidades da criança na escola e mais especificamente na sala de aula, quando realiza suas atividades".

Observa-se que a professora aborda questôes que se referem ao trabalho do professor e o quanto é benéfica a parceria com outros profissionais no sentido de favorecer o atendimento ao aluno dentro de sala de aula. Esse contato é válido, também, para esclarecer dúvidas e não gerar insegurança ao saber se está fazendo o correto quando se pensa em adaptar materiais ou adequar o ambiente físico, para não prejudicar o aluno. Sant'Ana (2005) investigou, por meio de entrevistas, as concepçóes sobre inclusão escolar de dez professores e seis diretores de escolas públicas do Ensino Fundamental, e houve apontamento em relação à falta de orientaçáo quanto ao surgimento de demandas dos alunos com necessidades especiais. Ademais, o fato de não se ter o apoio de uma equipe especializada, que atue com os professores e diretores, poderia ser um obstáculo na efetivação de práticas inclusivas.

A professora afirma, ao final, sobre a importância de se ouvir o professor quanto às necessidades da criança em sala de aula e em todo o contexto escolar, pois, assim como afirma Munguba (2007), é o educador que dará as informaçôes específicas sobre cada educando e conduzirá, na elaboraçáo de estratégias, de modo mais adequado.

\section{Conclusão}

Os recursos de tecnologia assistiva auxiliaram a criança na realização das atividades de pentear os cabelos, maquiar-se e de atividades que envolviam a utilização de lápis e canetas hidrográficas. Referente à adaptação de zíperes, houve facilitação quando a criança abria e fechava as bolsas, porém, torna-se necessário, ainda, acompanhar o uso da adaptaçáo em sala de aula, posto que o peso dos materiais escolares ainda seja um aspecto de dificuldade apontado pela professora. $\mathrm{O}$ virador de páginas contribuiu no manuseio do caderno e livros e foi possível identificar que a criança ainda atribuiu mais uma utilidade ao recurso, dando-lhe também a função de apagador. Evidenciou-se, também, pela fala da professora, que o uso desta adaptação foi temporário, na medida em que contribuiu para ganho de habilidade de manuseio de livros e caderno de forma independente.

Os recursos foram confeccionados com materiais considerados de baixo custo, sendo este um fator que contribui ao se pensar na facilidade de produção, como também no que se refere à aquisição, assim como afirmam Toyoda et al.(2009). Nesse mesmo sentido, a adaptação do lápis diminuiu a necessidade de reposição frequente, contribuindo, portanto, em aspectos financeiros.

A colaboração do professor é essencial para a identificação das necessidades do aluno com deficiência, a fim de nortear o trabalho do profissional da área da saúde no contexto escolar. 


\section{Referências}

ALMEIDA, C. A.; LIMA, P. V. C. Terapia Ocupacional e tecnologia assistiva: possibilidades de adaptaçóes para pessoas com paralisia cerebral. In: CASTILHO-WEINERT, L. V.; FORTI-BELLANI, C. D. Fisioterapia em neuropediatria. Curitiba: Omnipax, 2011, v. 1, p.125-146.

ANDRADE; F. L. Malformaçôes congênitas. In: TEIXEIRA, E. et al. Terapia Ocupacional na reabilitaçáo física. São Paulo: Roca, 2003. p. 457-483.

ARAÚJO, R. C. T.; MANZINI, E. J. Recursos de ensino na escolarizaçấo do aluno deficiente físico. In: MANZINI E.J. (org.) Linguagem, cogniçáo e ensino do aluno com deficiência. Unesp, 2001, p.1-11.

BARTALOTTI, C. C. Deficiência mental. In: CAVALCANTI, A.; GALVÃO, C. Terapia Ocupacional: fundamentação \& prática. Rio de Janeiro: Guanabara Koogan, 2007. p. 295-298.

BARTALOTTI, C. C.; DE CARLO, M. M. P. Terapia Ocupacional e os processos socioeducacionais. In: BARTALOTTI, C. C.; DE CARLO, M. M. P. (Org.). Terapia Ocupacional no Brasil: fundamentos e perspectivas. São Paulo: Plexus, 2001. p. 99-116.

BRASIL. Decreto no 3298 de 20/12/1999. Regulamenta a lei n. 7.853, de 24 de outubro de 1989. Dispóe sobre a política nacional para a integraçáo da pessoa portadora de deficiência, consolida as normas de proteçáo, e da outras providências. Diário Oficial da União de 21/12/1999.

BRASIL. Política Nacional de Educação Especial na perspectiva da Educaçấo Inclusiva. Portaria n. 948, de 09 de outubro de 2007. In: Inclusão: Revista da Educação Especial. Brasília: MEC/SEESP, v.4, n.1, p.7-17, 2008.

CARDOSO, P. T.; MATSUKURA, T. S. Práticas e perspectivas da terapia ocupacional na inclusão escolar. Rev. Ter. Ocup. Univ. Sáo Paulo, v. 23, n. 1, p. 7-15, jan/abr 2012.

CAT - Comitê de Ajudas Técnicas. Ata da Reunião VII, de dezembro de 2007, Comitê de Ajudas Técnicas. Secretaria Especial dos Direitos Humanos da Presidência da República (CORDE/SEDH/PR), 2007. Disponível em: <http://http://www.mj.gov.br/corde/comite.asp>. Acesso em: 20 fev. 2014.

CAZEIRO, A. P. M. et al. Terapia Ocupacional - A Terapia Ocupacional e as atividades de vida diária, atividades instrumentais da vida diária e tecnologia assistiva. Fortaleza: ABRATO, 2011. 119 p.

CHICONELLI; J. R.; MONTEIRO; A. V. A mão na artrogripose múltipla congênita. Rev. Bras. Ortop. v. 29, n. 6, jul, 1994. Disponível em: <http://www.rbo.org.br/Desktopdefault.aspx?tabid=132\&ItemID=1381\&edicaoid=162>. Acesso em: 15 fev. 2014 .

FILHO, O. B. A. O.; SANTOS, C. E. R. G. Artrogripose múltipla congênita. In: FERNANDES, A. C. et al. Medicina e Reabilitaçáo: princípios e prática. São Paulo: Artes Médicas, 2007. p. 69-76.

HOLM, M. B.; ROGERS, J. C.; JAMES, A. B. Tratamento das áreas de desempenho ocupacional. In: NEISTADT, M.E.; CREPEAU, E. B. Willard \& Spackman Terapia Ocupacional. Guanabara Koogan, 2002. p. 294-363.

MARINS, S. C. F.; EMMEL, M. L. G. Formação do terapeuta ocupacional: acessibilidade e tecnologias. Cad. Ter. Ocup. UFSCar, São Carlos, v. 19, n. 1, p. 37-52, jan/abr 2011.

MELLO; M. A. F.; MANCINI; M. C. Métodos e técnicas de avaliação nas áreas de desempenho ocupacional. In: CAVALCANTI, A.; GALVĀO, C. Terapia Ocupacional: fundamentação \& prática. Rio de Janeiro: Guanabara Koogan, 2007. p. 49-73.

MUNGUBA, M. C. Inclusão escolar. In: CAVALCANTI, A.; GALVÃO, C. Terapia Ocupacional: fundamentação \& prática. Rio de Janeiro: Guanabara Koogan, 2011, p. 519-525.

PELOSI, M. B. Inclusáo e Tecnologia Assistiva. 2008. 2 v. Tese (Doutorado em Educação) - Faculdade de Educação, Universidade do Rio de Janeiro, Rio de janeiro, Brasil, 2008.

PELOSI, M.B. A Tecnologia assistiva como facilitadora do processo de ensino e aprendizagem: uma parceria do Instituto Helena Antipoff e a Terapia Ocupacional da UFRJ. In: ARANHA, G.; SHOLL-FRANC, A. Caminhos da Neuroeducação. Rio de Janeiro: Ciência da Cognição, 2010, p.35-48.

PELOSI; M. B. Comunicação alternativa e suplementar. In: CAVALCANTI; A.; GLAVÃO; C. G. Terapia Ocupacional: fundamentaçấo \& prática. Rio de Janeiro: Guanabara Koogan, 2007. p. 462-468.

ROCHA, A. N. D. C. Processo de prescriçáo e confecçáo de recursos de tecnologia assistiva na educaçáo infantil. 2010. 199p. (Mestrado em Educação) - Faculdade de Filosofia e Ciência, Universidade Estadual Paulista, Marília, 2010. 
SANT'ANA, I. M. Educaçâo inclusiva: concepçōes de professores e diretores. Psicologia em estudo, Maringá, v. 10, n. 2, p. 227-234, mai/ago 2005.

TEIXEIRA, E.; ARIGA, M. Y.; YASSUKO, R. Adaptaçôes. In: TEIXEIRA, E. et al. Terapia Ocupacional na reabilitaçáo física. São Paulo: Roca, 2003. p. 129-173.

TOYODA, C. Y.; CRUZ, D. M. C.; LOURENÇO, G. F. Tecnologia assistiva de baixo custo: relato de consultoria colaborativa. In: Anais do V Congresso brasileiro multidisciplinar de educaçáo especial, Londrina, 2009.

TREVISAN, J. G.; BARBA, P. C. S. D. Reflexôes acerca da atuação do terapeuta ocupacional no processo de inclusão escolar de crianças com necessidades educacionais especiais. Cad. Ter. Ocup. UFSCar, São Carlos, v. 20, n.1, p. 89-94, 2012.

TROMBLY, C.; RADOMSKI, M. V. Terapia Ocupacional para disfunçóes físicas. 5. ed. São Paulo: Livraria Santos, 2005.

\section{Correspondência}

Bianca Sampaio Fiorini - Avenida Pedro de Toledo, n. 1855, Bairro: Palmital. Cep: 17509-022 - Marília, São Paulo, Brasil.

E-mail: bianca.sfiorini@gmail.com - ritac@marilia.unesp.br

Recebido em 24 de junho de 2014

Aprovado em 02 de setembro de 2014 
